\title{
Stimulated stromal cells induce $\gamma$-globin gene expression in erythroid cells via nitric oxide production
}

\author{
Vladan P. Čokića ${ }^{\mathrm{a}}$, Bojana B. Beleslin-Čokić ${ }^{\mathrm{b}}$, Reginald D. Smith ${ }^{\mathrm{c}}$, \\ Antaeus P. Economou ${ }^{d}$, Larry M. Wahl ${ }^{\mathrm{e}}$, Constance T. Noguchi ${ }^{\mathrm{f}}$, and Alan N. Schechter ${ }^{\mathrm{f}}$ \\ ${ }^{a}$ Laboratory of Experimental Hematology, Institute for Medical Research, University \\ of Belgrade, Belgrade, Serbia; ${ }^{\mathrm{b}}$ Institute of Endocrinology, Diabetes and Metabolic Diseases, \\ University Clinical Center, Belgrade, Serbia; ${ }^{\mathrm{c} B i o s c i e n c e s ~ T e c h n o l o g i e s, ~ G E ~ G l o b a l ~ R e s e a r c h ~ C e n t e r, ~ N i s k a y u n a, ~}$ \\ NY., USA; ${ }^{\mathrm{d} D e p a r t m e n t ~ o f ~ P e r i o d o n t o l o g y ~ a n d ~ B i o m a t e r i a l s, ~ R a d b o u d ~ U n i v e r s i t y ~ M e d i c a l ~ C e n t e r, ~ N i j m e g e n, ~ T h e ~ N e t h e r l a n d s ; ~}$ \\ ' Immunopathology Section, National Institute of Dental and Craniofacial Research, National Institutes of Health, Bethesda, Md., USA; \\ ${ }^{\mathrm{f}}$ Molecular Medicine Branch, National Institute of Diabetes and Digestive and Kidney Diseases, National Institutes of Health, Bethesda, Md., USA
}

(Received 12 June 2009; revised 15 June 2009; accepted 26 June 2009)

\begin{abstract}
Objective. We have previously shown that nitric oxide (NO) is involved in the hydroxyureainduced increase of $\gamma$-globin gene expression in cultured human erythroid progenitor cells and that hydroxyurea increases NO production in endothelial cells via endothelial NO synthase (NOS). We have now expanded those studies to demonstrate that stimulation of $\gamma$-globin gene expression is also mediated by NOS induction in stromal cells within the bone marrow microenvironment.

Materials and Methods. Using NO analyzer, we measured NO production in endothelial and macrophage cell cultures. In coculture studies of erythroid and stromal cells, we measured globin gene expression during stimulation by NO inducers.

Results. Hydroxyurea $(30-100 \mu \mathrm{M})$ induced NOS-dependent production of NO in human macrophages (up to $1.2 \mu \mathrm{M}$ ). Coculture studies of human macrophages with erythroid progenitor cells also resulted in induction of $\gamma$-globin mRNA expression (up to threefold) in the presence of hydroxyurea. NOS-dependent stimulation of NO by lipopolysaccharide (up to $0.6 \mu \mathrm{M}$ ) has been observed in human macrophages. We found that lipopolysaccharide and interferon- $\gamma$ together increased $\gamma$-globin gene expression (up to twofold) in human macrophage/erythroid cell cocultures. Coculture of human bone marrow endothelial cells with erythroid progenitor cells also induced $\gamma$-globin mRNA expression (2.4-fold) in the presence of hydroxyurea $(40 \mu \mathrm{M})$.

Conclusion. These results demonstrate an arrangement by which NO and fetal hemoglobin inducers may stimulate globin genes in erythroid cells via the common paracrine effect of bone marrow stromal cells. (c) 2009 ISEH - Society for Hematology and Stem Cells. Published by Elsevier Inc.
\end{abstract}

Bone marrow stromal cells serve as hematopoietic microenvironments where different blood cells are controlled in their growth and differentiation. Several growth factors, cytokines, and chemokines secreted by human hematopoietic progenitor cells regulate normal hematopoiesis in an autocrine/paracrine manner [1]. Moreover, each stromal cell in the bone marrow may provide the preferable microenvironment for a rapid expansion of lineage-restricted progenitor cells [2]. Intravascular erythropoietic cells asso-

Offprint requests to: Vladan P. Čokić, M.D., Laboratory of Experimental Hematology, Institute for Medical Research, Dr Subotića 4, P.O. Box 102, 11129 Belgrade, Serbia; E-mail: vl@imi.bg.ac.rs ciate with sinusoidal endothelial cells of the bone marrow as erythroid maturation proceeds [3]. The erythroblastmacrophage contact in the erythroblastic islands promotes proliferation and terminal maturation of erythroid cells [4]. The greatest expansion of hematopoietic progenitor cells was seen in direct contact with microvascular endothelial cells [5]. By some reports, media conditioned by human endothelial cell cultures also stimulate growth of human committed erythroid progenitors [6].

We found that during human erythroid differentiation in vitro, endothelial nitric oxide synthase (eNOS) mRNA, and protein levels were initially high, but then declined steadily, as did production of nitric oxide (NO) derivatives [7]. We also 
demonstrated that $\mathrm{NO}$ increases $\gamma$-globin gene expression in erythroid cells during differentiation [8]. In addition, we have shown that the well-known $\gamma$-globin gene inducer hydroxyurea stimulated fetal hemoglobin ( $\mathrm{HbF}$ ) by the NOdependent activation of soluble guanylyl cyclase in human erythroid progenitor cells [8]. According to our previous results, hydroxyurea dose- and time-dependently induced rapid but transient activation of eNOS in endothelial cells [9].

We were interested in explaining the mechanism of stimulation of $\gamma$-globin gene expression mediated by NOS induction in bone marrow microenvironment-related stromal cells. Besides our previous reports that hydroxyurea induced NO levels in human endothelial cells, we observe now that hydroxyurea induces NO production in macrophage cell line and primary cells and that induction also demonstrates NOS dependence. Hydroxyurea induces $\gamma$-globin mRNA expression in coculture studies of erythroid progenitor cells and both bone marrow endothelial cells and macrophages. A well-known stimulator of NO production, lipopolysaccharide (LPS), increases NO levels in a mouse macrophage cell line, as well as in human macrophages. LPS in combination with interferon- $\gamma(\mathrm{IFN}-\gamma)$ increases $\gamma$-globin gene expression in human erythroid progenitor cells in cocultures with human macrophages. These results may help to elucidate the role and origin of NO in $\gamma$-globin gene induction as well as providing a mechanism by which hydroxyurea may change the phenotype of hematopoietic cells via the paracrine effects of bone marrow stromal cells.

\section{Materials and methods}

\section{Human macrophage culture}

Human peripheral blood cells were obtained by leukapheresis of normal volunteers at the Department of Transfusion Medicine at the National Institutes of Health (Bethesda, MD, USA), and monocytes were purified using counterflow centrifugal elutriation on a Beckman Elutriation system as described previously [10]. The Institutional Review Board of the National Institutes of Health approved the leukapheresis protocol. Purified monocytes were cultured in Dulbecco's modified Eagle's medium (DMEM; BioWhittaker Inc., Walkersville, MD, USA) supplemented with $2 \mathrm{mM}$ L-glutamine (Mediatech, Washington, DC, USA) and 10 $\mathrm{ng} / \mathrm{mL}$ gentamicin sulfate (BioWhittaker Inc.). Cells were plated in 12-well polystyrene plates (Costar, Corning Inc., Corning, NY, USA) in a concentration of $5 \times 10^{6} / \mathrm{mL}$ DMEM and left for 30 minutes in $37^{\circ} \mathrm{C}$ to adhere. Monocytes were further differentiated to macrophages with the addition on day 0 of $5 \%$ normal human serum from healthy donors. These adherent cells were left in culture for 7 days, washed once and used for the two-phase erythroid cell culture. Human macrophage differentiation was verified by microscopic morphology.

\section{Mouse macrophage culture}

RAW 264.7 mouse macrophages were grown in DMEM supplemented with $13 \mathrm{mM} \mathrm{NaHCO} 3,20 \mathrm{mM}$ glucose, $100 \mathrm{U} / \mathrm{mL}$ penicillin, $100 \mu \mathrm{g} / \mathrm{mL}$ streptomycin and $10 \%$ fetal bovine serum at $37^{\circ} \mathrm{C}$ in $5 \%$
$\mathrm{CO}_{2}$ humidified air. RAW 264.7 macrophages were plated in wells of a 96-well microplate $\left(1 \times 10^{5}\right.$ cells/well $)$, and were left in culture for 6 hours to make macrophages adherent. Cells were subsequently cultured for 16 hours in $200 \mu \mathrm{L}$ fresh medium containing an appropriate concentration of LPS (Sigma-Aldrich, St Louis, MO, USA). Activated cells adherent in wells were washed twice with KrebsRinger phosphate buffer, followed by the addition of $10 \mu \mathrm{M}$ diaminofluorescein (DAF-2; Alexis Biochemicals, San Diego, CA, USA) and $1 \mathrm{mM}$ L-arginine (Sigma-Aldrich) dissolved in $200 \mu \mathrm{L}$ Krebs-Ringer phosphate buffer. Krebs-Ringer phosphate buffer consisted of $120 \mathrm{mM} \mathrm{NaCl}, 4.8 \mathrm{mM} \mathrm{KCl}, 0.54 \mathrm{mM} \mathrm{CaCl}, 1.2 \mathrm{mM} \mathrm{MgSO}_{4}$, $11 \mathrm{mM}$ glucose, and $15.9 \mathrm{mM}$ sodium phosphate $(\mathrm{pH} 7.2)$. After incubation with LPS or hydroxyurea (Sigma-Aldrich), the supernatants were transferred to black microplates and the fluorescence of NO/DAF-2 interaction was measured with a fluorescence microplate reader calibrated for excitation at $470 \mathrm{~nm}$ and emission at $550 \mathrm{~nm}$. The intracellular NO levels were measured by the cell permeable probe 4,5-diaminofluorescein diacetate (DAF-2DA; Alexis Biochemicals) using a microplate reader and Epics Elite flow cytometer (Coulter, Hialeah, FL, USA).

\section{Endothelial cell culture}

Transformed human bone marrow endothelial cells (TrHBMEC) are a permanent bone marrow endothelial cell line from an adult female donor's cells immortalized with the $\mathrm{T}$ antigen of simian virus 40 [11]. TrHBMEC were cultured as described previously [9]. Percentage of confluence of TrHBMEC in culture dishes was determined by enumeration via an inverted optical microscope.

\section{Coculture studies}

We performed a two-phase liquid culture protocol for erythroid cells described previously by our laboratory [7]. Briefly, after incubation in phase I culture, CD34 ${ }^{+}$cells were harvested and purified by negative selection using the StemSep Cell Separation method (Stem Cell Technologies Inc, Vancouver, Canada). The $\mathrm{CD} 4^{+}$cells were resuspended in the phase II medium that contained a mixture of cytokines, including human recombinant erythropoietin (Amgen Inc, Thousand Oaks, CA, USA). Adherent endothelial cell and macrophage cultures were prepared in sixwell plates, respectively. Cocultures of hematopoietic progenitor cells and TrHBMEC were treated with hydroxyurea, whereas cocultures with macrophages were treated with LPS, LPS/IFN$\gamma$, or hydroxyurea. The inserts containing erythroid progenitor cells were placed in the wells containing endothelial cells or macrophages, but separated from them by a $1-\mu \mathrm{m}$ pore semipermeable membrane (Biocoat BD Biosciences Discovery Labware, Bedford, MA, USA), while sharing the same phase II medium. Erythroid progenitor cells were placed in cocultures at day 4, after initiation of phase II cultures, and incubated for 24 and 48 hours in phase II medium at $37^{\circ} \mathrm{C}$ in a humidified atmosphere with $5 \% \mathrm{CO}_{2}$ during treatment by either hydroxyurea or LPS and IFN- $\gamma$ (Sigma-Aldrich).

\section{$R N A$ extraction and real-time quantitative} reverse transcriptase polymerase chain reaction For isolation of total RNA from erythroid cells, we used the RNeasy procedure (Qiagen, Valencia, CA, USA) according to manufacturer's instructions. The concentration and integrity of total RNA were assessed using an 8453 UV/Visible Spectrophotometer (Hewlett-Packard GmbH, Waldbronn, Germany) and 
Agilent 2100 Bioanalyzer Software (Agilent Technologies, Waldbronn, Germany). One microgram of total RNA was reverse transcribed with SuperScript II RNase $\mathrm{H}^{-}$Reverse Transcriptase kit (Invitrogen, Carlsbad, CA, USA). The specific primers of human $\gamma$ - and $\beta$-globin genes as well as TAQMAN probes were designed using Primer Express software and prepared on an ABI 394 synthesizer as described previously [12]. Platinum Quantitative PCR SuperMix-UDG (Invitrogen) was used, containing a final concentration of $200 \mu \mathrm{M} 2^{\prime}$-deoxynucleoside $5^{\prime}$-triphosphates, $0.5 \mu \mathrm{M}$ Rox reference dye (Invitrogen), $0.2 \mu \mathrm{M}$ each of TAQMAN probe, sense and antisense primers. Expression levels were determined using the associated SDS software (ABI Prism, Applied Biosystems) and Microsoft Excel (Redmond, WA, USA).

\section{Ozone-based chemiluminescent}

\section{determination of nitrite in cell culture supernatants}

TrHBMEC were pretreated for 30 minutes with $\mathrm{N}^{\mathrm{G}}$-Nitro-Larginine-methyl ester (L-NAME; Alexis Biochemicals). Cells were exposed to bradykinin in the presence of L-arginine (Sigma-Aldrich). The confluent human and mouse macrophages in six-well plates were washed twice with DMEM and the culture medium was replaced with DMEM supplemented with $100 \mathrm{U} / \mathrm{mL}$ penicillin, $100 \mu \mathrm{g} / \mathrm{mL}$ streptomycin, and $5 \mathrm{mmol} / \mathrm{L}$ glutamine. After 3 hours, the medium was replaced with a new DMEM and cells were treated with hydroxyurea and LPS/IFN- $\gamma$ (SigmaAldrich) in the presence of L-arginine. Human and RAW 264.7 mouse macrophages were pretreated 30 minutes with eNOS inhibitor L-NAME. The supernatant of treated cells was immediately frozen on dry ice and stored at $-80^{\circ} \mathrm{C}$. Frozen samples were thawed and then injected in reductants, in line with the Sievers Model 280 NO analyzer (Sievers, Boulder, CO, USA). NO was measured by nitrite reduction in acidified potassium iodide containing $7 \mathrm{~mL}$ glacial acetic acid, $2 \mathrm{~mL}$ distilled water, $50 \mathrm{mg}$ potassium iodide, and a crystal of iodine that was added to yield a concentration of 6 to $20 \mathrm{mmol} / \mathrm{L}$ (Sigma-Aldrich). Helium was bubbled through the reaction mixture.

\section{Statistical analysis}

One-way analysis of variance and Dunnett's posttests were applied using Prism 4 software (GraphPad Software Inc., San Diego, CA, USA). For comparison of hydroxyurea effects on erythroid progenitor cells, with or without TrHBMEC, we used the paired $t$-test with two-tail $p$ values. The paired $t$-test was also used for comparison of hydroxyurea induction of NO levels with or without L-NAME.

\section{Results}

Induction of NO production and $\gamma$-globin gene expression by stimulated RAW 264.7 mouse macrophages in coculture studies with erythroid cells Macrophages are stromal cells with a very potent capacity for producing NO. Stimulation of NO production in mouse macrophage cell lines by hydroxyurea has been reported in other studies, during 24 hours of treatment, and could also amplify the direct effects of the drug on hematopoietic cells [13]. We first examined the RAW 264.7 mouse macrophage cell line, as a model with potent NO production [14].
Hydroxyurea increased NO levels in RAW 264.7 mouse macrophages $(0.15 \mu \mathrm{M}$, four- to sixfold), and this was diminished by NOS inhibitor L-NAME as a short-term effect (Fig. 1A). Thus, hydroxyurea stimulation of NO

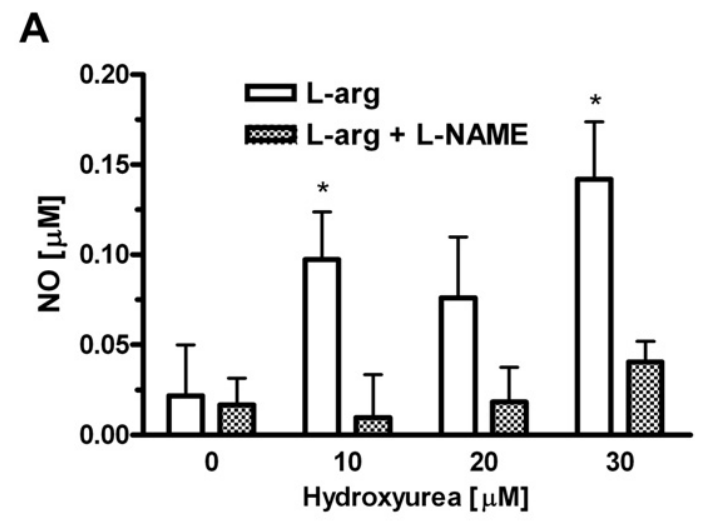

B

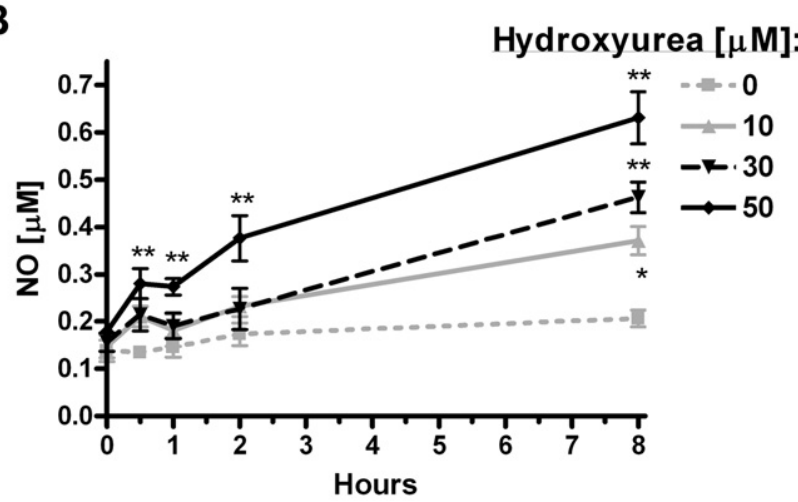

C

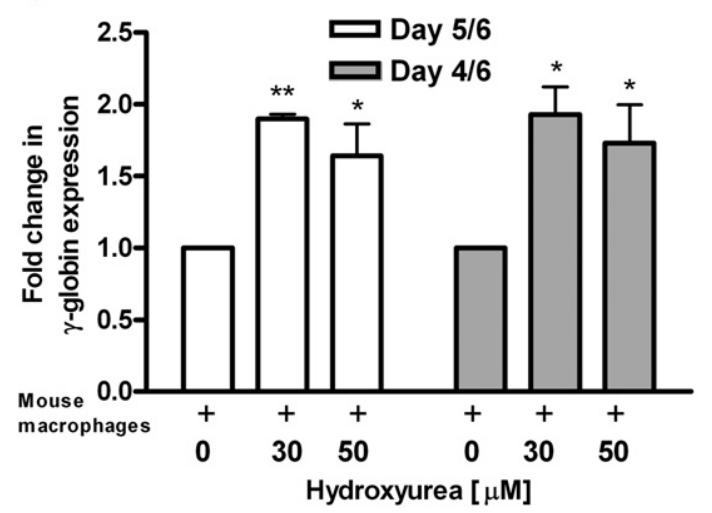

Figure 1. Coculture studies of erythroid progenitor cells and RAW 264.7 mouse macrophages cell line stimulated by hydroxyurea. (A) Measurement of nitric oxide (NO), by NO analyzer (NOA), in RAW 264.7 mouse macrophages during 30 minutes of incubation with hydroxyurea $(10-30 \mu \mathrm{M})$ in the presence of $1 \mathrm{mM} \mathrm{L}$-arginine with and without $0.5 \mathrm{mM} \mathrm{N}^{\mathrm{G}}$-Nitro-L-arginine-methyl ester (L-NAME). (B) Hydroxyurea stimulation of NO levels in RAW 264.7 mouse macrophages during 8 hours of incubation. (C) The $\gamma$-globin gene expression in coculture of erythroid progenitor cells and mouse macrophages after 24 hours and 48 hours of treatment by hydroxyurea at day 6 of cell culture. Values represent mean \pm standard error of mean $(\mathrm{n}=3)$. ${ }^{*} p<0.05$ and $* * p<0.01$ compared to cells untreated with hydroxyurea. 
production in RAW 264.7 mouse macrophages demonstrated NOS-dependence similarly to hydroxyurea effects in endothelial cells [9]. We found that hydroxyurea $(10-50 \mu \mathrm{M})$ induced even higher and prolonged NO levels (up to $0.6 \mu \mathrm{M}$ ) in RAW 264.7 mouse macrophages after 8 hours of treatment (Fig. 1B), besides the already reported long-term hydroxyurea augmentation of $\mathrm{NO}$ production in mouse macrophage cell lines [13]. In our previous reports, we treated the erythroid cells during their maturation with hydroxyurea and NO donors and observed the major increase of $\gamma$-globin gene expression at day 6 of erythroid cell culture [8]. According to that, we focused our coculture studies to erythroid progenitor cells at day 6 after 24 or 48 hours of treatment by appropriate agents. In our current experiments, hydroxyurea doubled $\gamma$-globin production in erythroid progenitor cells in cocultures with mouse macrophages after 24 hours of treatment (up to 17 fmol $\gamma$-globin mRNA $/ 1 \times 10^{5}$ cells by $30 \mu \mathrm{M}$ hydroxyurea), as well as after 48 hours of treatment (Fig. 1C) at day 6 of erythroid cells culture.

In the following experiments, we used LPS, a wellknown NOS-dependent NO inducer, in combination with NOS substrate L-arginine. It has been reported that RAW 264.7 mouse macrophages, stimulated with LPS, grew with an estimated doubling time of 35 hours and produced $\mathrm{NO}$ at a rate of $30 \mathrm{nmol}$ per $10^{6}$ cells per day [14]. We demonstrated a high dose-dependent increase in extracellular NO levels $(4.5-6 \mu \mathrm{M})$ during 2 hours of stimulation by LPS as measured by an NO analyzer and fluorescent probe DAF-2 (Fig. 2A). We also observed a similar induction of intracellular NO production by LPS as measured by a cell-permeable probe DAF-2DA using both fluorimetric plate reader (Fig. 2B) and flow cytometry (90\% positive). Higher LPS concentrations $(>200 \mathrm{ng} / \mathrm{mL}$ ) demonstrated increased cytotoxicity toward erythroid progenitor cells (data not shown), which can mimic hydroxyurea cytotoxic effects consequently reducing the total $\gamma$-globin mRNA expression. In the range of 50 to $200 \mathrm{ng} / \mathrm{mL}$ LPS failed to increase $\gamma$-globin mRNA expression, whereas it increased the $\gamma / \beta$ ratio between 1.3- and 1.8-fold in coculture studies of RAW 264.7 mouse macrophages and erythroid progenitor cells after 48 hours of incubation at day 6 (Fig. 2C). Thus, the very increased NO production $(>5 \mu \mathrm{M})$, by mouse macrophages cell line and LPS, has a low stimulatory or even inhibitory effect on $\gamma$-globin gene expression as well as increased cytotoxicity in erythroid cells.

\section{Induction of $\mathrm{NO}$ production and}

$\gamma$-globin gene expression by stimulated human

macrophages in coculture studies with erythroid cells

We previously reported that NO is involved in hydroxyurea stimulation of $\gamma$-globin gene expression in human erythroid progenitor cells [8]. We now expand our coculture studies with human macrophages to a more appropriate model
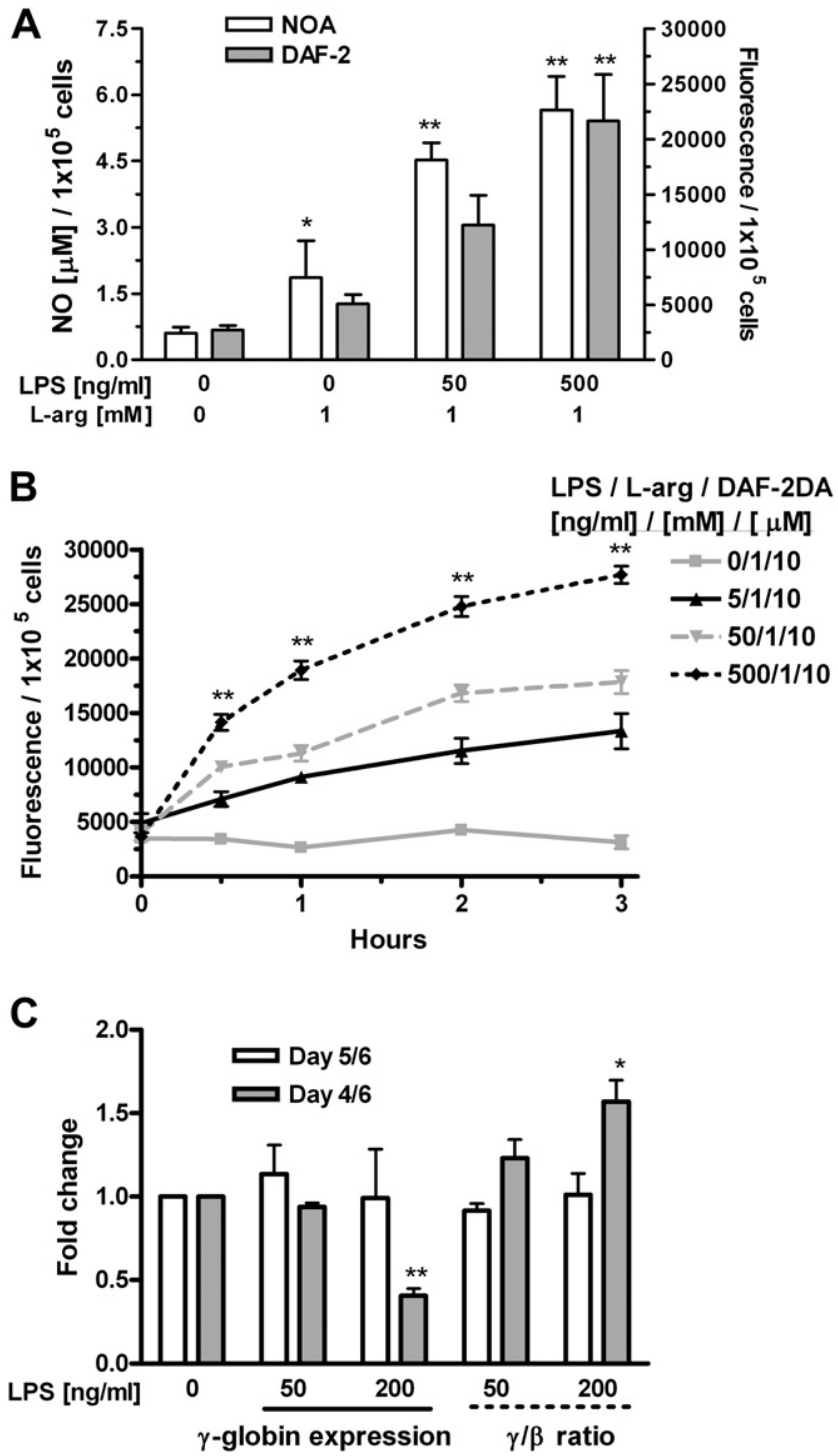

Figure 2. Coculture studies of erythroid progenitor cells and RAW 264.7 mouse macrophages cell line stimulated by lipopolysaccharide (LPS). (A) Detection of LPS stimulated extracellular nitric oxide (NO) levels by NO analyzer (NOA) (white bars) and fluorescent probe diaminofluorescein (DAF-2; $10 \mu \mathrm{M}$, gray bars) in RAW 264.7 mouse macrophages after 2 hours of incubation, in the presence of L-arginine. (B) Detection of LPS stimulated intracellular NO levels with fluorescent probe DAF-2DA $(10 \mu \mathrm{M})$ in RAW 264.7 mouse macrophages during 3 hours of incubation, in the presence of L-arginine. $* * p<0.01$ applies for all samples treated with various concentrations of LPS. (C) The $\gamma$-globin gene expression and $\gamma / \beta$ ratio in cocultures after 24 and 48 hours of treatment by LPS at day 6 of cell culture. Values are mean \pm standard error of mean $(n=3)$. ${ }^{*} p<0.05$ and ${ }^{* *} p<0.01$ compared to cells untreated with LPS.

related to human erythroid progenitor cells. During 2 hours incubation of human macrophages with hydroxyurea, we observed a dose-dependent increase of NO levels $(0.7 \mu \mathrm{M}$, Fig. 3A). This short-term increased NO production by hydroxyurea was also inhibited by L-NAME (Fig. 3A), demonstrating again NOS dependence. Hydroxyurea $(30-100 \mu \mathrm{M})$ induced even higher and prolonged NO 
A

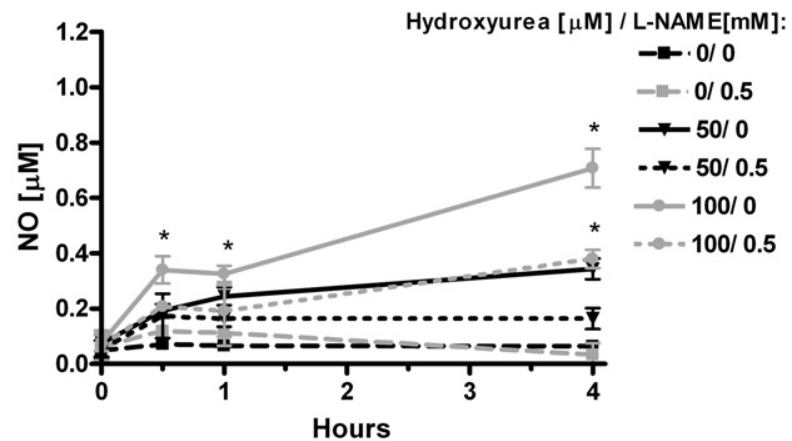

B
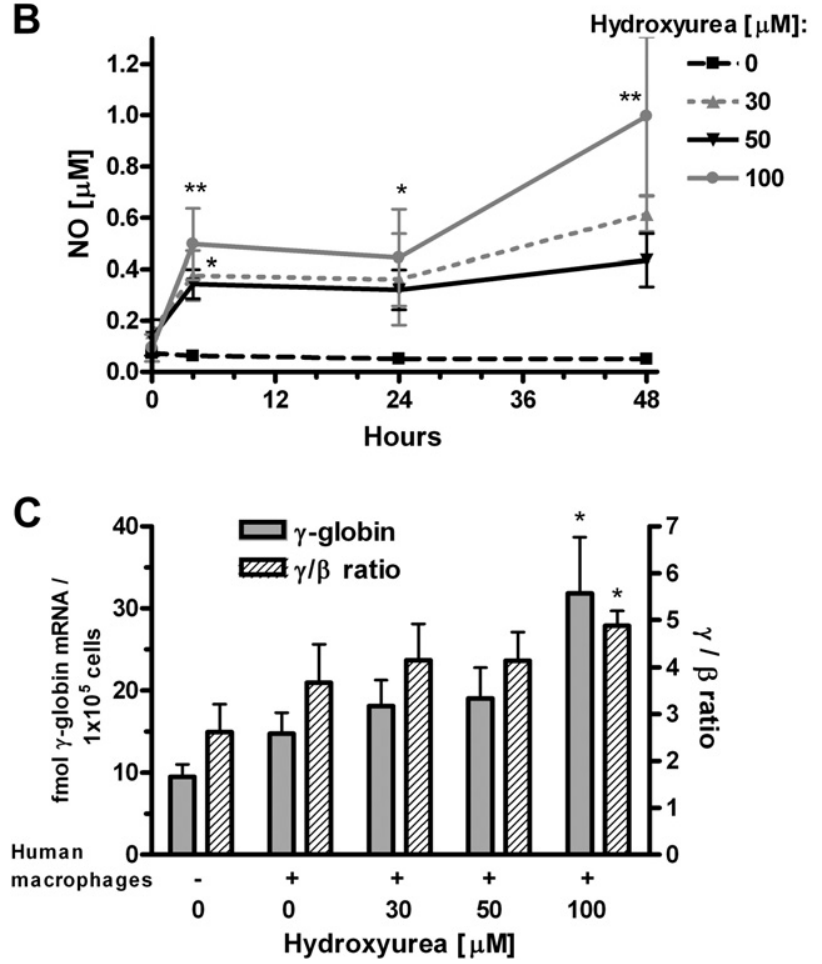

Figure 3. Coculture studies of erythroid progenitor cells and human macrophages stimulated by hydroxyurea. (A) Dose-dependent stimulation of nitric oxide (NO) levels by hydroxyurea and $0.5 \mathrm{mM} \mathrm{N} \mathrm{N}^{\mathrm{G}}$-Nitro-Larginine-methyl ester (L-NAME) in human macrophages after 4 hours of incubation. (B) Hydroxyurea stimulation of NO levels in human macrophages during 48 hours of incubation. (C) The $\gamma$-globin gene expression and $\gamma / \beta$ ratio in coculture studies of erythroid progenitor cells and human macrophages after 48 hours of treatment by hydroxyurea at day 6 of cell culture. Values are mean \pm standard error of mean $(\mathrm{n}=3)$. ${ }^{*} p<0.05$ and $* * p<0.01$ compared to cells untreated with hydroxyurea.

levels (up to $1 \mu \mathrm{M}$ ) in human macrophages after 48 hours of treatment (Fig. 3B). Hydroxyurea $(20-100 \mu \mathrm{M})$ did not increase inducible NOS mRNA levels in human macrophages after 24 and 48 hours of treatment (data not shown), demonstrating that its effects are linked to NOS protein level. Hydroxyurea $(30-50 \mu \mathrm{M})$ stimulated $\gamma$-globin gene expression up to 1.72 -fold in erythroid progenitor cells only. In parallel experiments, hydroxyurea increased $\gamma$-globin production (up to 2.2 -fold by $100 \mu \mathrm{M}$ hydroxyurea) in erythroid progenitor cells in cocultures with human macrophages, as well as the $\gamma / \beta$ ratio after 48 hours of treatment (Fig. 3C). Under the same culture conditions, hydroxyurea failed to enhance to a statistically significant level of $\gamma$-globin production after 24 hours of treatment (data not shown). These stimulations of $\gamma$-globin gene expression are similar to that with NO production by human macrophages treated with hydroxyurea (Fig. 3B). Hydroxyurea also increased $\gamma$-globin gene expression with lower concentrations (30 and $50 \mu \mathrm{M}$ ) and less prominent $\mathrm{NO}$ induction, but this did not reach statistical significance after 48 hours of incubation (Fig. 3C). Thus hydroxyurea, as a long-term stimulator of NO production, increased $\gamma$-globin gene expression in erythroid progenitor cells in cocultures with macrophages.

It has been reported that synthesis of NO was greatly increased when mouse macrophages were costimulated with LPS and IFN- $\gamma$ compared to LPS alone, parallel with increases in cytotoxicity [15]. That was confirmed in our experiments with human macrophages (data not shown). As expected, combination of LPS and IFN- $\gamma$ increased NO production $(0.5 \mu \mathrm{M})$ in human macrophages after 4 hours of incubation, which was prevented by a competitive inhibitor L-NAME, demonstrating NOS dependence (Fig. 4A). Mutual stimulation by LPS and IFN- $\gamma$ demonstrated prolonged NO stimulation in human macrophages during 48 hours of incubation (up to 0.6; Fig. 4B), but not so high compared to hydroxyurea (Fig. 3B). Treatment of only erythroid progenitor cells with LPS $(50 \mathrm{ng} / \mathrm{mL})$ and IFN- $\gamma(500 \mathrm{U} / \mathrm{mL})$ did not change significantly $\gamma$-globin gene expression, but reduced $\gamma / \beta$ ratio (1.26-fold) at day 6 or erythroid culture. Furthermore, we treated cocultures of human macrophages and erythroid progenitor cells with separately LPS $(50 \mathrm{ng} / \mathrm{mL})$ and IFN- $\gamma(500$ and $1,000 \mathrm{U} / \mathrm{mL})$ and found slight increase in $\gamma$-globin gene expression up to 1.14- and 1.2-fold, respectively, but reduction in $\gamma / \beta$ ratio (more profound with IFN- $\gamma$ only, up to 1.23 -fold). The combination of LPS and IFN- $\gamma$, in coculture experiments with human macrophages, significantly increased $\gamma$-globin mRNA expression (2.1-fold) in erythroid progenitor cells after 48 hours of incubation at day 6 (Fig. 4C). However, the increase in the $\gamma / \beta$ ratio (1.6-fold) did not reach statistical significance (Fig. 4C). Therefore, macrophage-derived $\mathrm{NO}$, increased by cytokines LPS and IFN- $\gamma$, is sufficient to increase $\gamma$-globin gene expression in human erythroid progenitor cells. Cocultures of erythroid progenitor cells with macrophages stimulated generally higher levels of $\gamma$-globin gene expression comparing to erythroid cells only, even with no stimulators (Figs. 3C and 4C).

$\gamma$-Globin gene expression in coculture studies of erythroid progenitor cells and endothelial cells

We recently reported that hydroxyurea induces NO production in endothelial cells, both as short-term and long-term effects $[9,16]$. Hydroxyurea $(30-50 \mu \mathrm{M})$ induced prolonged NO 
A

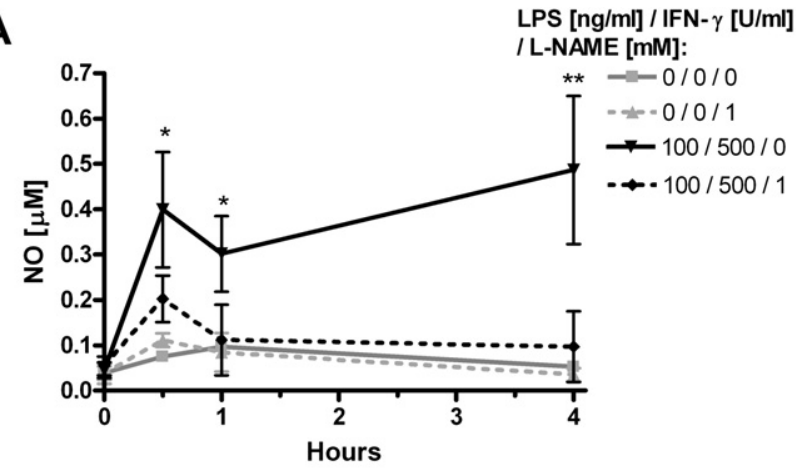

B
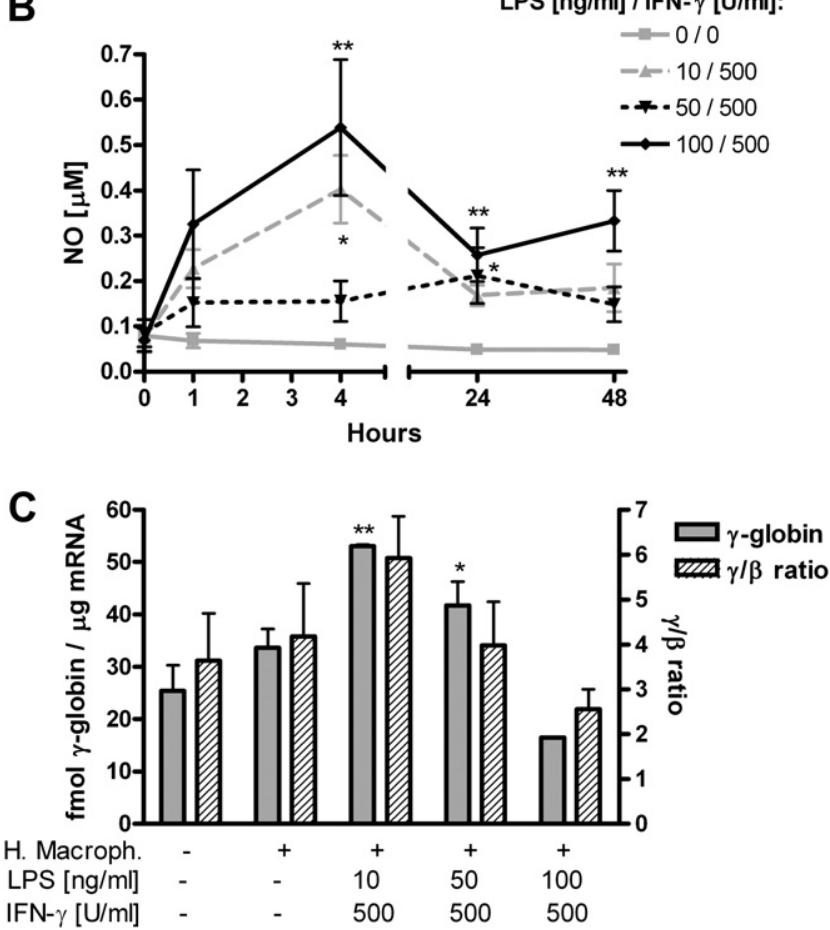

Figure 4. Coculture studies of erythroid progenitor cells and human macrophages stimulated by lipopolysaccharide (LPS)/interferon (IFN- $\gamma$ ). (A) Measurement of nitric oxide (NO) production, by $\mathrm{NO}$ analyzer (NOA), during treatment of human macrophages (at $80-90 \%$ of confluence) with LPS/IFN- $\gamma$ and $1 \mathrm{mM}$ L-NAME during 4 hours of incubation. (B) LPS/IFN- $\gamma$ stimulation of NO levels in human macrophages during 48 hours of incubation. (C) The $\gamma$-globin gene expression and $\gamma / \beta$ ratio in coculture studies of erythroid progenitor cells and human macrophages after 48 hours of treatment by LPS/IFN- $\gamma$ at day 6 of cell culture. Values are mean \pm standard error of mean $(\mathrm{n}=3)$. $* p<0.05$ and $* * p<0.01$ compared to cells untreated with LPS/IFN- $\gamma$.

production (up to $1.3 \mu \mathrm{M}$ ) in TrHBMEC after 24 hours of treatment [16]. We present findings that hydroxyurea significantly increased $\gamma$-globin mRNA expression (2.4-fold) in coculture experiments with TrHBMEC after 24 hours of incubation at day 6 of erythroid cells culture (Fig. 5). That increase was higher in comparison with hydroxyurea effect on erythroid cells only (1.8-fold, Fig. 5), and reached statistical significance. To examine the general ability of endothelial cells derived NO to affect $\gamma$-globin gene expression, we

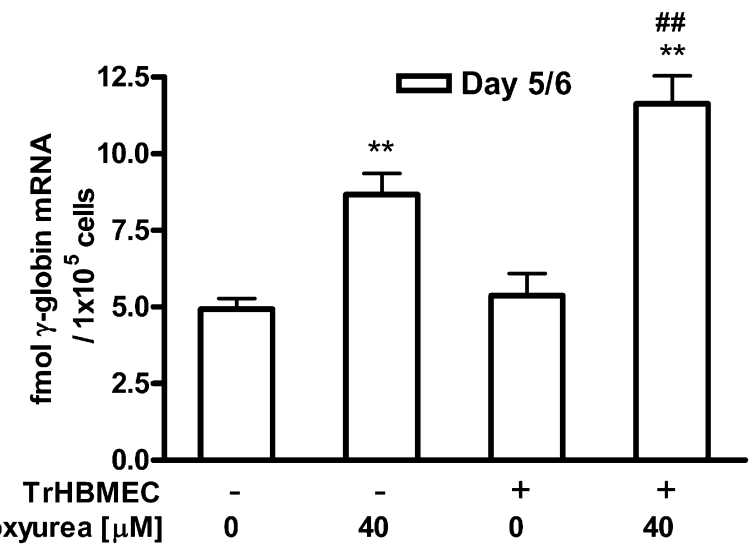

Figure 5. Coculture studies of erythroid progenitor cells and bone marrow endothelial cell line. The $\gamma$-globin gene expression in coculture studies of erythroid progenitor cells and Transformed human bone marrow endothelial cells (TrHBMEC) after 24 hours of treatment by $40 \mu \mathrm{M}$ hydroxyurea at day 6 of cell culture. Values represent mean \pm standard error of mean $(\mathrm{n}=3)$. $* * p<0.01$ compared to cells untreated with hydroxyurea, as well as between samples treated by hydroxyurea with or without TrHBMEC $\left({ }^{\# \#} p<0.01\right)$.

stimulated the TrHBMEC by bradykinin, a well-known stimulator of NO production in endothelial cells [17]. The low- and short-term induced NO production (up to $0.1 \mu \mathrm{M}$ ), by bradykinin, failed to increase $\gamma$-globin mRNA expression and the $\gamma / \beta$ ratio in erythroid progenitor cells in coculture studies with TrHBMEC after 24 hours of treatment at day 6 of cells culture (data not shown). Therefore, the endothelial cell line-derived NO, induced by physiologic stimulator bradykinin, is not sufficient to increase $\gamma$-globin gene expression in erythroid progenitor cells. The effective concentrations of NO levels, related to $\gamma$-globin induction by stromal cells, are between 0.5 and $1.3 \mu \mathrm{M}$ according to our present results.

\section{Discussion}

Hydroxyurea induced NO production in human and RAW 264.7 mouse macrophages that was NOS protein-dependent, but not detected at a transcriptional level. Further, we observed the enhancement of $\gamma$-globin expression by hydroxyurea in coculture studies of erythroid progenitor cells and macrophages. LPS stimulated NO production in RAW 264.7 mouse macrophages via the NOS enzyme. Moreover, LPS in combination with IFN- $\gamma$ increased NO production in human macrophages as well as $\gamma$-globin gene expression in coculture studies of erythroid cells and the human macrophages. Hydroxyurea also increased $\gamma$-globin expression in cocultures of erythroid and bone marrow endothelial cell line, indicating another potential effector of the hematopoietic microenvironment.

It has been already reported that LPS and IFN- $\gamma$ significantly increased NO production in cell cultures with human monocyte-derived macrophages after 24 and 48 hours of treatment [18]. An additional report revealed that human 
monocyte-derived macrophages did not consistently produce detectable nitrite levels in response to LPS and IFN- $\gamma$ [19]. The latest observation might potentially explain inconsistencies in dose-dependent effects of LPS and IFN- $\gamma$ to NO production and $\gamma$-globin gene stimulation in cocultures of human monocyte-derived macrophages and erythroid progenitor cells. Moreover, it has been reported that IFN- $\gamma$ significantly decreased $\mathrm{HbF}$ production in cultures of adult burst-forming unit erythroid-derived erythroblasts [20]. According to our present results, IFN- $\gamma$ did not change significantly $\gamma$-globin gene expression in solitary erythroid progenitor cells and in coculture with human macrophages, but decreased the $\gamma / \beta$ ratio. Combined treatment by LPS and IFN- $\gamma$ increased $\gamma$-globin gene expression and did not significantly influence the $\gamma / \beta$ ratio. The increased $\gamma$-globin gene expression is in correlation with elevated NO production by human macrophages during dual treatment by LPS and IFN$\gamma$. It has been published that simultaneous exposure to LPS and IFN- $\gamma$ resulted in a decrease in macrophage cell number after 48 hours of treatment [14]. So, these cytostatic/cytotoxic effects with larger LPS and IFN- $\gamma$ concentrations may reduce $\gamma$-globin induction, as well as cause persistent elevated NO production.

These observations accord to the intimate contact between erythroid and stromal cells, effects, and associations in physiological hematopoietic microenvironment. The endothelial cells as well as macrophages, normal components of bone marrow stroma, play an active role in the modulation of human hematopoietic stem cell growth [4-6]. The murine endothelial cell lines also stimulate proliferation and differentiation of erythroid precursors, where close cell contact is necessary for erythropoiesis [21]. Mice deficient in eNOS, expressed by bone marrow stromal cells, demonstrated a defect in progenitor cell mobilization [22]. Hemoglobin synthesis of an erythroleukemia cell line was increased after coculture with endothelial cells and monolayers of bone-marrow-derived macrophages, as well as with cell-free culture media conditioned by blood-monocyte-derived macrophages [23].

Recent studies indicate that hydroxyurea increases $\mathrm{HbF}$ levels through NO-dependent activation of soluble guanylyl cyclase $[8,24]$. We have shown that NO increases $\gamma$-globin levels, the $\gamma / \beta$-globin ratio and $\mathrm{HbF}$ levels in human erythroid cells, whereas inhibition of soluble guanylyl cyclase prevents NO-induced increase in $\gamma$-globin gene expression [8]. Erythroid cells demonstrates initial high but then continuous decrease of eNOS levels during maturation in contrast with steady elevation of hemoglobin levels, a potent scavenger of NO [7]. Also, the nitrite derived-NO levels are low $(<0.2 \mu \mathrm{M})$ between days 4 and 6 of erythroid cells culture [7], which potentiates the significance of stromal cells. We showed that the endothelial cells and macrophages contain NOS activity, representing potential pools for NO production. Continuous and moderate NO production (between 0.6 and $1.3 \mu \mathrm{M}$ ), by stimulated stroma cells, preferably increases $\gamma$-globin gene expression. This supplemented NO production, in the hematopoietic microenvironment, has the potential to enhance $\mathrm{HbF}$ synthesis in erythroid progenitor cells, which still have low hemoglobin levels and presumably low NO scavenging activity.

The erythroid progenitor cell cocultures with either macrophages or endothelial cells, stimulated by NO inducers, lead to elevated levels of $\gamma$-globin gene expression as compared to the erythroid cells only. This observation suggests that NO could diffuse out of the bone marrow stromal cells and into the erythroid progenitor cells largely participating in $\gamma$-globin gene induction, due to the stromal cells augmented capability for NO production. This suggests a mechanism by which NO may induce globin genes and affect changes in the phenotype of erythroid progenitors via the common paracrine effect of bone marrow stromal cells. Previous reports and our current results also contribute to the understanding of the significance of NO participation in $\gamma$-globin gene induction by hydroxyurea. These results support future studies, with an emphasis focused on the hematopoietic microenvironment, in a search of therapy for sickle cell disease and perhaps even myeloproliferative disorders currently treated with hydroxyurea.

\section{Acknowledgments}

This research was supported by the Intramural Research Program of the National Institutes of Health (Bethesda, MD, USA) and National Institute of Diabetes and Digestive and Kidney Diseases (Bethesda, MD, USA) and by grant from the Serbian Ministry of Science and Technological Development (Belgrade, Serbia) (145048B).

\section{Conflict of Interest}

No financial interest/relationships with financial interest relating to the topic of this article have been declared.

\section{References}

1. Majka M, Janowska-Wieczorek A, Ratajczak J, et al. Numerous growth factors, cytokines, and chemokines are secreted by human CD34(+) cells, myeloblasts, erythroblasts, and megakaryoblasts and regulate normal hematopoiesis in an autocrine/paracrine manner. Blood. 2001;97:3075-3085.

2. Kameoka J, Yanai N, Obinata M. Bone marrow stromal cells selectively stimulate the rapid expansion of lineage-restricted myeloid progenitors. J Cell Physiol. 1995;164:55-64.

3. Sorrell JM, Weiss L. Cell interactions between hematopoietic and stromal cells in the embryonic chick bone marrow. Anat Rec. 1980;197:1-19.

4. Hanspal M, Hanspal JS. The association of erythroblasts with macrophages promotes erythroid proliferation and maturation: a $30-\mathrm{kD}$ heparin-binding protein is involved in this contact. Blood. 1994;84: 3494-3504.

5. Davis TA, Robinson DH, Lee KP, Kessler SW. Porcine brain microvascular endothelial cells support the in vitro expansion of human primitive hematopoietic bone marrow progenitor cells with a high replating potential: requirement for cell-to-cell interactions and colony-stimulating factors. Blood. 1995;85:1751-1761. 
6. Ascensao JL, Vercellotti GM, Jacob HS, Zanjani ED. Role of endothelial cells in human hematopoiesis: modulation of mixed colony growth in vitro. Blood. 1984;63:553-558.

7. Čokić VP, Andric SA, Stojilkovic SS, Noguchi CT, Schechter AN. Hydroxyurea nitrosylates and activates soluble guanylyl cyclase in human erythroid cells. Blood. 2008;111:1117-1123.

8. Čokić VP, Smith RD, Beleslin-Čokić BB, et al. Hydroxyurea induces fetal hemoglobin by the nitric oxide-dependent activation of soluble guanylyl cyclase. J Clin Invest. 2003;111:231-239.

9. Čokić VP, Beleslin-Čokić BB, Tomic M, Stojilkovic SS, Noguchi CT, Schechter AN. Hydroxyurea induces the eNOS-cGMP pathway in endothelial cells. Blood. 2006;108:184-191.

10. Zhang Y, McCluskey K, Fujii K, Wahl LM. Differential regulation of monocyte matrix metalloproteinase and TIMP-1 production by TNF-alpha, granulocyte-macrophage CSF, and IL-1 beta through prostaglandin-dependent and independent mechanisms. J Immunol. 1998;161:3071-3076.

11. Schweitzer KM, Vicart P, Delouis $C$, et al. Characterization of a newly established human bone marrow endothelial cell line: distinct adhesive properties for hematopoietic progenitors compared with human umbilical vein endothelial cells. Lab Invest. 1997;76:25-36.

12. Smith RD, Li J, Noguchi CT, Schechter AN. Quantitative PCR analysis of $\mathrm{HbF}$ inducers in primary human adult erythroid cells. Blood. 2000;95:863-869.

13. Pai K, Shrivastava A, Kumar R, et al. Activation of P388D1 macrophage cell line by chemotherapeutic drugs. Life Sci. 1997;60:1239-1248.

14. Zhuang JC, Wogan GN. Growth and viability of macrophages continuously stimulated to produce nitric oxide. Proc Natl Acad Sci U S A. 1997;94:11875-11880.

15. Lorsbach RB, Murphy WJ, Lowenstein CJ, Snyder SH, Russell SW. Expression of the nitric oxide synthase gene in mouse macrophages activated for tumor cell killing. Molecular basis for the synergy between interferon-gamma and lipopolysaccharide. J Biol Chem. 1993;268:1908-1913.

16. Čokić VP, Beleslin-Čokić BB, Noguchi CT, Schechter AN. Hydroxyurea increases eNOS protein levels through inhibition of proteasome activity. Nitric Oxide. 2007;16:371-378.

17. Gooch KJ, Frangos JA. Flow- and bradykinin-induced nitric oxide production by endothelial cells is independent of membrane potential. Am J Physiol. 1996;270:C546-C551.

18. Bose M, Farnia P. Proinflammatory cytokines can significantly induce human mononuclear phagocytes to produce nitric oxide by a cell maturation-dependent process. Immunol Lett. 1995;48:59-64.

19. Padgett EL, Pruett SB. Evaluation of nitrite production by human monocyte-derived macrophages. Biochem Biophys Res Commun. 1992;186:775-781.

20. Miller BA, Perrine SP, Antognetti G, et al. Gamma-interferon alters globin gene expression in neonatal and adult erythroid cells. Blood. 1987;69:1674-1681.

21. Ohneda O, Bautch VL. Murine endothelial cells support fetal liver erythropoiesis and myelopoiesis via distinct interactions. Br J Haematol. 1997;98:798-808.

22. Aicher A, Heeschen C, Mildner-Rihm C, et al. Essential role of endothelial nitric oxide synthase for mobilization of stem and progenitor cells. Nat Med. 2003;9:1370-1376.

23. Zuhrie SR, Pearson JD, Wickramasinghe SN. Haemoglobin synthesis in K562 erythroleukaemia cells is affected by intimate contact with monolayers of various human cell types. Leuk Res. 1988;12: $567-574$

24. Ikuta T, Ausenda S, Cappellini MD. Mechanism for fetal globin gene expression: role of the soluble guanylate cyclase-cGMP-dependent protein kinase pathway. Proc Natl Acad Sci U S A. 2001;98:1847-1852. 